\title{
Correspondence
}

\section{Costoclavicular brachial plexus block in paediatric anaesthesia: A retrospective pilot study}

A R T I C L E I N F O

\section{Keywords}

Costoclavicular brachial plexus block

Brachial plexus block

Paediatric anaesthesia

Regional anaesthesia

Patient safety

The costoclavicular brachial plexus block (CСBPB) is a recently described ultrasound-guided block [1] that targets the chords of the brachial plexus in the costoclavicular space (CCS), where they are arranged superficially in a bundle. Experience in children is limited to case reports [2], hence data about safety and applications are lacking. Our goals were to determine the complication rate and identify the clinical applications of CCBPB in children.

This is a single-center retrospective study conducted in a paediatric hospital in Portugal. We analysed a three-year period (January 2017 to December 2019) with data extracted from a regional anaesthesia database in which patients cannot be identified. Therefore, according to institution protocol, IRB approval was not required. Data are expressed as means (standard deviation; range) for numeric variables and as counts and percentages for categorical variables. Binomial distribution was used to estimate the $95 \%$ confidence interval (CI) for complications.

Overall, 484 upper limb blocks were performed, of which the majority were ССВPB $(n=200 ; 41.3 \%)$. All blocks were placed under general anaesthesia. Table 1 shows the type of block performed detailed by year. A clear change in practice is noted throughout the years and, in 2019 , ССВРB was preferred in $67.9 \%$ of cases.

A total of 200 CCBPB were performed in 198 patients. The mean age was $9.07 \pm 4.09$ years. Weight ranged from 11 to $97 \mathrm{~kg}$ and most patients (73.23\%) were classified as ASA I. Overall, 98\% of CCBPB were unilateral and single shot blocks. Four catheters were placed and were infused for a mean of 2.5 days, with no malfunctions reported. See

Table 1

Brachial plexus block approaches performed by year.

\begin{tabular}{lcccc}
\hline Site & $\mathbf{2 0 1 7}$ & $\mathbf{2 0 1 8}$ & $\mathbf{2 0 1 9}$ & Total (\%) \\
\hline Interscalene & 1 & 1 & 2 & $4(0.8 \%)$ \\
Supraclavicular & 69 & 22 & 6 & $97(20 \%)$ \\
Infraclavicular & 22 & 41 & 29 & $92(19 \%)$ \\
Costoclavicular & 17 & 77 & 106 & $200(41.3 \%)$ \\
Axillary & 43 & 19 & 5 & $67(13.8 \%)$ \\
Distal & 13 & 3 & 8 & $24(5.1 \%)$ \\
Total & $\mathbf{1 6 5}$ & $\mathbf{1 6 3}$ & $\mathbf{1 5 6}$ & $\mathbf{4 8 4}$ \\
\hline
\end{tabular}

Table 2 for patient demographics and specifics related to ССВРВ placement.

CCBPB were performed for orthopaedic, plastic, and paediatric surgery of the upper limb. Most patients received CCBPB for elbow (48.5\%) and forearm $(29 \%)$ surgery. The most prevalent diagnosis were bone fractures $(n=160 ; 80 \%)$ and soft tissue trauma $(n=21 ; 10.5 \%)$. The most prevalent surgeries were osteosynthesis of supracondylar $(n=58$; $29 \%)$ and radius and/or ulnar shaft fractures $(n=50 ; 25 \%)$.

ССВPB provides surgical anaesthesia for upper limb below the shoulder since the brachial plexus is approached at the cords before the emergence of the medial brachial and antebrachial cutaneous nerves. The consistent topographical arrangement in the CCS allows easy and safe access to the brachial plexus, with a low block failure rate. A success rate of $97 \%$ was reported [3] for surgical anaesthesia in adults, as well as rapid onset of sensory and motor blockade of the major nerves of the brachial plexus. These characteristics make the CCBPB an unchallenging block with a short learning curve.

The CCS is also an optimal location for catheter placement, as the catheter tip is placed close to the three cords, and through the subclavius and pectoralis major muscles, reducing the risk of catheter dislodgment.

The incidence of complications was 1:200 (0.5\%) with a 95\% CI of $0-1.5 \%$. An axillary artery puncture in a 2-year-old, $15 \mathrm{~kg}$, ASA II toddler, was reported in this approach. No haematoma or permanent sequelae were reported. Other site-specific complications such as pleural puncture and phrenic nerve paralysis are lower in CCBPB since the parietal pleura is deeper than neurovascular structures, and the compact topography allows reducing the local anaesthetic volume used.

This study is limited by its retrospective single-center design and small size. Prospective clinical studies with larger populations are needed to validate our findings.

We demonstrate the use of ССВPB in bone and soft tissue surgery of the arm, elbow, forearm, and hand with a low complication rate in paediatric patients, which should encourage its widespread use. In conclusion, ССBPB can be used safely in children for upper arm surgery. 
Table 2

Patient demographics, surgical procedures and ССВРВ characteristics.

\begin{tabular}{|c|c|c|c|}
\hline Patient demographics & \multicolumn{3}{|l|}{$\mathrm{n}=198$} \\
\hline Sex & \multicolumn{2}{|l|}{$\mathbf{n}$} & $\%$ \\
\hline Male & \multicolumn{2}{|l|}{131} & $66.2 \%$ \\
\hline Female & \multicolumn{2}{|c|}{67} & $33.8 \%$ \\
\hline Age at surgery, years & \multicolumn{3}{|c|}{$9.07(\mathrm{SD} \pm 4.09)$} \\
\hline Range & \multicolumn{3}{|c|}{1 year -20 years } \\
\hline Weight, kg & \multicolumn{3}{|c|}{$33.13(\mathrm{SD} \pm 15.97)$} \\
\hline Range, kg & \multicolumn{3}{|c|}{$11-97$} \\
\hline ASA & \multicolumn{2}{|l|}{$\mathbf{n}$} & $\%$ \\
\hline I & \multicolumn{2}{|l|}{145} & $73.23 \%$ \\
\hline II & \multicolumn{2}{|l|}{48} & $24.24 \%$ \\
\hline III & \multicolumn{2}{|l|}{5} & $2.53 \%$ \\
\hline \multicolumn{2}{|c|}{ Surgical location and most common procedures } & $\mathrm{n}=\mathbf{2 0 0}$ & $\%$ \\
\hline \multicolumn{2}{|l|}{ Arm } & 13 & $6.5 \%$ \\
\hline Humeral osteosynthesis & & 6 & $3 \%$ \\
\hline Humeral osteotomy & & 5 & $2.5 \%$ \\
\hline Other humeral surgeries & & 2 & $1 \%$ \\
\hline Elbow & & 97 & $48.5 \%$ \\
\hline Osteosynthesis of supracondylar & & 58 & $29 \%$ \\
\hline Osteosynthesis of other distal hur & tures & 20 & $10 \%$ \\
\hline Osteosynthesis of radial head and & anon fractures & 18 & $9 \%$ \\
\hline Abscess drainage & & 1 & $0.5 \%$ \\
\hline Forearm & & 58 & $29 \%$ \\
\hline Osteosynthesis of radius and/or u & fractures & 50 & $25 \%$ \\
\hline Radius osteotomy & & 3 & $1.5 \%$ \\
\hline Soft tissue surgery & & 3 & $1.5 \%$ \\
\hline Osteosynthesis material extractio & & 2 & $1 \%$ \\
\hline Hand and wrist & & 32 & $16 \%$ \\
\hline Osteosynthesis of distal radius an & Ir fractures & 5 & $2.5 \%$ \\
\hline Osteosynthesis of hand bone frac & & 6 & $3 \%$ \\
\hline Osteotomies of distal radius, ulna & bones & 4 & $2 \%$ \\
\hline Soft tissue surgery & & 17 & $8.5 \%$ \\
\hline ССВPB characteristics & $\mathrm{n}=\mathbf{2 0 0}$ & & $\%$ \\
\hline Laterality & & & \\
\hline Unilateral & 196 & & $98 \%$ \\
\hline Bilateral & 4 & & $2 \%$ \\
\hline Catheter placement & & & \\
\hline Single shot & 196 & & $98 \%$ \\
\hline Catheter placed & 4 & & $2 \%$ \\
\hline Type of local anaesthetic & & & \\
\hline Ropivacaine & 145 & & $72.5 \%$ \\
\hline $0.5 \%$ & 6 & & $3 \%$ \\
\hline $0.375 \%$ & 93 & & $46.5 \%$ \\
\hline $0.2 \%$ & 44 & & $22 \%$ \\
\hline $0.15 \%$ & 1 & & $0.5 \%$ \\
\hline $0.1 \%$ & 1 & & $0.5 \%$ \\
\hline Levobupivacaine & 55 & & $27.5 \%$ \\
\hline $0.5 \%$ & 3 & & $1.5 \%$ \\
\hline $0.25 \%$ & 49 & & $24.5 \%$ \\
\hline $0.125 \%$ & 3 & & $1.5 \%$ \\
\hline Adjuvant & $\mathrm{n}=198$ & & \\
\hline I.V. dexamethasone $(0.1 \mathrm{mg} / \mathrm{kg})$ & 115 & & $58.1 \%$ \\
\hline
\end{tabular}

\section{Disclosures}

No grants, sponsors, and funding sources.

\section{Declaration of Competing Interest}

The authors declare that they have no known competing financial interests or personal relationships that could have appeared to influence the work reported in this paper.

\section{Acknowledgments}

This research did not receive any specific grant from funding agencies in the public, commercial, or not-for-profit sectors.

\section{References}

[1] Karmakar MK, Sala-Blanch X, Songthamwat B, Tsui BC. Benefits of the costoclavicular space for ultrasound-guided infraclavicular brachial plexus block: description of a costoclavicular approach. Reg Anesth Pain Med 2015;40:287-8. https:// doi.org/10.1097/aap.0000000000000232. Department of Anesthesia and Intensive Care, The Chinese University of Hong Kong, Prince of Wales Hospital, Shatin, New Territories, Hong Kong, SAR, China Department of Anesthesiology Hospital Clinic Barcelona Barcelona, Spain Department of Human Anatomy.

[2] Yayik AM, Cesur S, Öztürk F, Celik EC, Ahiskalioglu A. Ultrasound guided costoclavicular approach to brachial plexus: first pediatric report. J Clin Anesth 2019;55: 136-7. https://doi.org/10.1016/j.jclinane.2019.01.008.

[3] Li JW, Songthamwat B, Samy W, Sala-Blanch X, Karmakar MK. Ultrasound-guided costoclavicular brachial plexus block: sonoanatomy, technique, and block dynamics. Reg Anesth Pain Med 2017;42:233-40. https://doi.org/10.1097/ aap.0000000000000566.

Filipa Carioca, (MM) ${ }^{\mathrm{a}, *, 1}$, Marisa Silva, (MM) ${ }^{\mathrm{a}, 1}$, Catarina Bispo, (MM) ${ }^{\mathrm{a}, 1}$, José Mafra, (MD) ${ }^{\mathrm{b}}$, Teresa Cenicante, (MD) ${ }^{\mathrm{b}}$

a Anaesthesiology Resident, Dona Estefânia Children's Hospital, University Medical Centre of Central Lisbon, Portugal

${ }^{\mathrm{b}}$ Senior Graduated Anaesthesiologist, Dona Estefânia Children's Hospital, University Medical Centre of Central Lisbon, Portugal

* Corresponding author at: Serviço de Anestesiologia, Hospital Dona Estefânia, Rua Jacinta Marto, 1169-045 Lisboa, Portugal. E-mail address: filipacarioca@campus.ul.pt (F. Carioca).

${ }^{1}$ These authors contributed equally to the manuscript. 